\title{
Liberação Controlada da Eosina Impregnada em Microesferas de Copolímero de Quitosana e Poli(ácido acrílico)
}

\author{
Atche J osué, Mauro C. M. Laranjeira, Valfredo T. Fávere, Irene Yukiko Kimura \\ QUITECH, Departamento de Química, UFSC \\ Rozangela C. Pedrosa \\ Departamento de Bioquímica, UFSC
}

Resumo: Microesferas de quitosana com grau de desacetilação médio de 85,6\% foram enxertadas com poli(ácido acrílico) para aplicação como sistemas de liberação controlada de fármacos. O corante eosina impregnado nas microesferas de quitosana modificada foi utilizado como marcador para estudo in vitro de liberação de fármacos. As microesferas de quitosana foram obtidas pelo método de inversão de fases com $\mathrm{NaOH}$, seguidas de reticulação com glutaraldeído, redução com cianoboroidreto de sódio e enxertia com poli(ácido acrílico) na presença de uma solução de nitrato de cério (IV) amoniacal como iniciador redox. Os estudos in vitro de liberação da eosina a partir de microesferas de quitosana, mostraram que o corante foi liberado em função do tempo a pH 6,8 e 9,8 que simulam as condições fisiológicas do trato gastrointestinal, enquanto que nenhuma eosina foi liberada a pH 1,2.

Palavras-chave: Microesferas de quitosana, liberação controlada, poli(ácido acrílico), eosina.

\section{Controlled Release of Eosin Impregnated in Microspheres of Chitosan/Poly(acrylic acid) Copolymer}

Abstract: Chitosan microspheres obtained by coacervation-phase separation, cross-linked with glutaraldehyde and grafted with poly(acrylic acid) were used as the basis of in vitro studies on the controlled release of eosin. Microspheres impregnated with an aqueous solution of the dye depicted a time-dependent release of eosin at $\mathrm{pH}$ values of 6.8 and 9.8, typical of the gastrointestinal tract. No eosin release could be observed at $1.2 \mathrm{pH}$.

Keywords: Chitosan microspheres, controlled release, poly(acrylic acid), eosin.

\section{Introdução}

Nesses últimos anos, tem-se constatado um notável crescimento em torno da criação de novos sistemas de liberação de fármacos. Durante esse período, a indústria farmoquímica se destacou no uso e no aproveitamento de matérias primas de baixo custo e fácil acesso para o desenvolvimento de novos materiais poliméricos, o que permitiu o uso de várias técnicas para encapsulamento de muitos compostos em sistemas de multipartículas, como microesferas e microcápsulas, no intuito de proteger, estabilizar, mascarar os sabores indesejáveis ou modificar as propriedades de liberação ${ }^{[1]}$. Os sistemas de multipartículas têm suscitado um grande interesse nas formulações orais por apresentarem muitas vantagens, tais como dose única, variabilidade do tempo de trânsito no trato gastrointestinal e a possibilidade de mistura de fármacos de diferentes propriedades de liberação ${ }^{[2,3]}$.

A quitosana (Figura 1), polissacarídeo obtido pela hidrólise alcalina da quitina ${ }^{[4]}$, age como floculante em tratamentos de efluentes líquidos e como resina quelante

Autor para correspondência: Mauro C. M. Laranjeira, Grupo de Pesquisas em Quitinas e Aplicações Tecnológicas (QUITECH), Departamento de Química, UFSC, Campus Trindade 476, CEP: 88040-900, Florianópolis, SC. E-mail: mauro@qmc.ufsc.br 


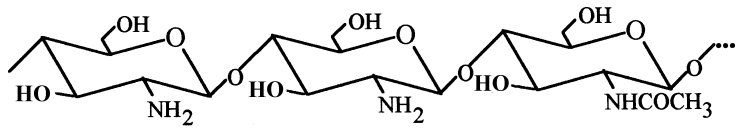

Figura 1. Quitosana

na remoção de metais pesados ${ }^{[5-7]}$. Este polissacarídeo vem sendo usado como sistema polimérico na liberação de fármacos, tais como prednilisolona ${ }^{[8]}$, albumina $^{[9]}$ e melatonina ${ }^{[10]}$. Sua biocompatibilidade foi comprovada em implantes como biomaterial nos tecidos vivos ${ }^{[11]} \mathrm{e}$ a sua baixa toxicidade foi verificada em animais $\left(\mathrm{DL}_{50}\right.$ : dose letal em ratos $\left.16 \mathrm{~g} / \mathrm{kg}\right)$. Estas propriedades permitiram o emprego da quitosana em formulações farmacêuticas e médicas ${ }^{[12,13]}$. Comprimidos encapsulados por quitosana se comportam como géis em soluções de baixo pH e são adequados para liberação de fármacos solúveis em água ${ }^{[14]}$. Outros trabalhos descreveram que as formulações orais revestidas de quitosana flutuam e intumescem gradualmente em solução de $\mathrm{pH} 1,2^{[15]}$.

Salienta-se, ainda, que a quitosana e seus derivados apresentam algumas vantagens importantes com relação às atividades farmacológicas, atuando como antiácido, antiúlcera, protegendo a mucosa gástrica e inibindo a adesão das bactérias nas células epiteliais bucais e vaginais ${ }^{[16]}$.

O objetivo deste trabalho foi desenvolver microesferas a partir do copolímero de quitosana e poli(ácido acrílico ${ }^{[17,18]}$, como uma matriz para sistemas de liberação controlada de fármacos. A eosina (Figura 2), corante solúvel em água, com elevada absortividade molar na região do visível, foi usada como marcador para o estudo in vitro de liberação de fármacos em diferentes soluções tampão, simulando o trato gastrointestinal. Este corante apresenta uma

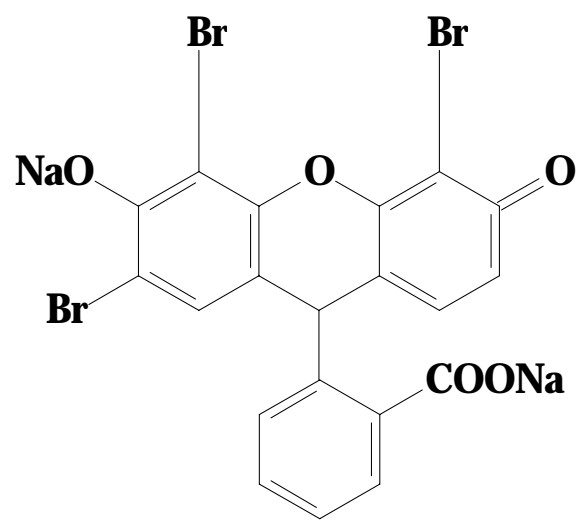

Figura 2. Eosina massa molar de $691,87 \mathrm{~g} / \mathrm{mol}$, relativamente pequena, comparável aos dos fármacos como diclofenato de sódio, ácido acetil salicílico e rifampicina.

\section{Experimental}

\section{Materiais e métodos}

Quitina, ácido acrílico (grau de pureza 98\%), eosina (grau de pureza 98\%) foram obtidas da Sigma Chemical Company e utilizadas sem purificações prévias.

As medidas de absorção e a emissão das amostras contendo o corante eosina foram realizadas no espectrofluorímetro Perkin Elmer (England) LS-5B. As soluções aquosas foram preparadas com água ultrapura, obtida por Milli-Plus de Millipore (USA).

As soluções tampão de $\mathrm{pH}$ 9,8 foram obtidas por diluição do tampão tris- (hidroximetil)-aminometano 0,1 $\mathrm{mol} / \mathrm{L}$ e seu $\mathrm{pH}$ foi ajustado com $\mathrm{HCl} 0,1 \mathrm{~mol} / \mathrm{L}$; as soluções de $\mathrm{pH}$ 6,8 foram obtidas pela mistura de 15,45 $\mathrm{mL}$ de solução de $\mathrm{Na}_{2} \mathrm{HPO}_{4}$ 0,2 $\mathrm{mol} / \mathrm{L}$ e $4,55 \mathrm{~mL}$ de solução de ácido acético $0,2 \mathrm{~mol} / \mathrm{L}$ e as de $\mathrm{pH}$ 1,2 (solução tampão Clark-Lubs) pela mistura de $50,0 \mathrm{~mL}$ de $\mathrm{KCl} 0,2 \mathrm{~mol} / \mathrm{L}$ e de $64,5 \mathrm{~mL}$ de $\mathrm{HCl} 0,2 \mathrm{~mol} / \mathrm{L}$.

A fluorescência da eosina é observada em $520 \mathrm{~nm}$, após excitação em $490 \mathrm{~nm}$. Uma boa linearidade da curva padrão de fluorescência para a eosina foi encontrada na faixa de concentração 7,5X $10^{-9}-7,5 \times 10^{-8}$ mol/L. A equação (1) representa a regressão linear dos pontos experimentais obtidos de absorbância (Abs) em função da concentração $(\mathrm{C})$ :

$$
\text { Abs }=0,08897+0,21247 \mathrm{C}, \mathrm{Rc}=0,99839
$$

\section{Preparação da quitosana}

A quitina $(50,0 \mathrm{~g})$ foi submetida à reação de desacetilação pelo método de Broussignac, sob atmosfera de nitrogênio ${ }^{[19]}$. A quitosana obtida foi seca em estufa a $50{ }^{\circ} \mathrm{C}$, dissolvida em ácido acético $3 \%(\mathrm{~m} / \mathrm{v})$ e filtrada em cadinho sinterizado com porosidade média para eliminar resíduos insolúveis em ácido acético. A quitosana foi precipitada em $\mathrm{NaOH} 1 \mathrm{~mol} / \mathrm{L}$, filtrada, lavada com água e seca novamente a $50{ }^{\circ} \mathrm{C}$.

O grau de desacetilação médio $(\% \overline{\mathrm{GD}})$ foi determinado por titulação condutimétrica, empregando um condutivímetro Micronal (modelo B330) e um titulador automático Schott Geräte (modelo T80/20). Uma amostra de $200 \mathrm{mg}$ de quitosana foi transferida 
para um béquer de $600 \mathrm{mg}$, contendo $450 \mathrm{~mL}$ de solução de $\mathrm{NaCl}$ 0,001 mol/L, 5,0 mL de $\mathrm{HCl} 1,0 \mathrm{~mol} / \mathrm{L}$ e após a dissolução do polímero, a titulação foi conduzida com adição de $\mathrm{NaOH} 0,100 \mathrm{~mol} / \mathrm{L}$ a cada 20 segundos, sob atmosfera de nitrogênio ${ }^{[20]}$.

\section{Preparação das microesferas de quitosana e enxertia com poli (ácido acrílico)}

A quitosana $(4,0 \mathrm{~g})$ foi dissolvida em 100,0 mL de ácido acético $5 \%(\mathrm{~m} / \mathrm{v})$. A solução polimérica de quitosana foi gotejada com auxílio de uma bomba peristáltica (Ismatec) sobre uma solução de $\mathrm{NaOH} 2$ $\mathrm{mol} / \mathrm{L}$. As microesferas formadas foram deixadas durante 30 minutos numa solução de $\mathrm{NaOH} 2 \mathrm{~mol} / \mathrm{L}$ sob agitação para completar a precipitação, posteriormente lavadas até meio neutro e colocadas em contato com uma solução de glutaraldeído, cuja proporção foi de $1,5 \mathrm{~mL}$ por grama de microesferas. A mistura reacional foi mantida durante 24 horas sob temperatura ambiente para completar a reação de reticulação. Após lavagem com água destilada, as microesferas foram suspensas em uma solução de cianoboroidreto de sódio $1 \mathrm{~mol} / \mathrm{L}$ durante 48 horas, à temperatura ambiente, para redução dos grupos imino.

Numa segunda etapa, as microesferas reticuladas $(2,50 \mathrm{~g})$ foram colocadas num balão de $250,0 \mathrm{~mL}$ de 3 bocas, contendo 50,0 mL de água milli-Q e 10,0 $\mathrm{mL}$ de ácido acrílico sob atmosfera de nitrogênio. Após 1 hora e 30 minutos, foi adicionado $8 \mathrm{~mL}$, de solução de nitrato de cério (IV) amoniacal $0,1 \mathrm{~mol} / \mathrm{L}$ dissolvido em ácido nítrico $1 \mathrm{~mol} / \mathrm{L}$, e o sistema reacional foi mantido sob atmosfera de nitrogênio durante 3 horas $^{[21]}$. A reação foi interrompida pela adição de uma pequena quantidade do agente redutor hidroquinona e, em seguida, o material foi lavado com água para eliminar o excesso de ácido acrílico que não reagiu e o homopolímero poli(ácido acrílico) formado na reação de enxertia. Um outro experimento foi realizado usando-se a mesma quantidade de microesferas mas sem adição de ácido acrílico para determinar, por diferença de massa, o grau de enxertia.

$\mathrm{Na}$ terceira etapa, as microesferas funcionalizadas foram colocadas numa solução aquosa de concentração $1 \mathrm{~mol} / \mathrm{L}$ de eosina em pH 6,8 durante 24 horas para impregnação e posteriormente filtradas e secas a vácuo.

\section{Caracterização das microesferas modificadas}

As amostras de microesferas quitosana modificadas foram pulverizadas para análise através da espectroscopia na região do infravermelho (FTIR). Os espectros de FTIR foram obtidos utilizando-se aparelho Perkin Elmer Modelo FT-PC-16. As amostras foram prensadas com $\mathrm{KBr}$ na forma de pastilhas.

As microesferas secas foram caracterizadas por microscopia eletrônica de varredura em relação ao tamanho médio, porosidade e morfologia. As amostras foram colocadas em estabes, recobertas de ouro e micrografadas num microscópio eletrônico de varredura (Philips - modelo XL30). O diâmetro médio de 1,52 $\pm 0,20 \mathrm{~mm}$ foi determinado a partir da média de 20 microesferas, utilizando-se medidas dos diâmetros nos eixos vertical e horizontal de cada microesfera.

\section{Determinação da quantidade de eosina em microesferas}

Dez amostras (40,0 mg cada) de microesferas de quitosana contendo eosina foram colocadas em tubo de ensaio com 5,0 $\mathrm{mL}$ de água Milli-Q em banho termostatizado a $37^{\circ} \mathrm{C}$. Após uma hora de contato no meio aquoso as microesferas foram trituradas com auxilio de bastão de vidro. Posteriormente, os conteúdos dos tubos foram centrifugados e os sobrenadantes retirados para determinar a quantidade de eosina liberada no meio aquoso. Este procedimento foi repetido várias vezes com as amostras trituradas até a extração total da eosina das microesferas. Isto foi comprovado quando do sobrenadante testado não apresentou absorção no comprimento de onda máximo de $520 \mathrm{~nm}$.

\section{Estudo de liberação "in vitro" da eosina}

Amostras (40,0 mg) de microesferas de quitosana contendo eosina foram suspensas em $10,0 \mathrm{~mL}$ de soluções tampão de $\mathrm{pH}$ 1,2; pH 6,8; pH 9,8 e mantidas sob agitação em banho termostatizado de $37{ }^{\circ} \mathrm{C}$, simulando as condições do trato gastrointestinal ${ }^{[22]}$.

A determinação da quantidade de eosina liberada das microesferas foi realizada retirando um volume do sistema de liberação em pH 1,2 de 30 em 30 minutos até duas horas para simular as condições de tempo de trânsito estomacal. As amostras foram retiradas no $\mathrm{pH}$ 6,8 de 2 horas até 6 horas e no $\mathrm{pH}$ 9,8 de 6 horas até 12 horas para simular as condições de trânsito intestinal e cecal, respectivamente.

As alíquotas tomadas permitiram determinar a quantidade de matéria em mols de eosina, liberados em função do tempo a diferentes $\mathrm{pH}$ estudados. 


\section{Resultados e Discussão}

O grau médio de desacetilação (\% $\overline{\mathrm{GD}})$ de $85,6 \%$ ou $5,32 \mathrm{mmol}$ de grupos amino/g de quitosana, foi calculado a partir de três titulações condutimétricas de quitosana com solução padrão de $\mathrm{NaOH} 0,0887 \mathrm{~mol} / \mathrm{L}$.

A reticulação das microesferas com glutaraldeído, seguida da redução dos grupos imino, foi necessária para inibir a solubilização do copolímero em soluções ácidas com $\mathrm{pH} \leq 1,5$.

O grau de enxertia (\%GE) calculado a partir da equação (2) é apresentado na Tabela 1:

$$
\% \mathrm{GE}=\frac{\mathrm{P}_{2}-\mathrm{P}_{1}}{\mathrm{P}_{1}} \times 100
$$

Onde $\mathrm{P}_{1}$ é a massa de microesferas não enxertadas e $\mathrm{P}_{2}$ a massa de microesferas enxertadas.

A Tabela 1 apresenta os graus de enxertia com diferentes massas de microesferas de quitosana. Os valores encontrados referem-se a média de cinco determinações para cada grau de enxertia determinado. O valor médio encontrado foi de 54,6 $\pm 2,0 \%$.

Os espectros na região do infravermelho da quitosana e da quitosana enxertada com poli(ácido acrílico) são ilustrados na Figura 3.

Observa-se nos dois espectros as presenças das bandas na região de $3400 \mathrm{~cm}^{-1}$, que corresponde ao estiramento $\mathrm{OH}$ de hidroxilas, $2900 \mathrm{~cm}^{-1}$ atribuída ao estiramento $\mathrm{C}-\mathrm{H}, 1600$ a $1670 \mathrm{~cm}^{-1}$ correspondente ao estiramento $\mathrm{C}=\mathrm{O}$ da amida $\mathrm{I}$, pois a quitosana não está completamente desacetilada e $1590 \mathrm{~cm}^{-1}$ banda atribuída à deformação $\mathrm{NH}_{2}$.

Nota-se na Figura $3 b$ a presença da banda em $1731 \mathrm{~cm}^{-1}$ correspondente ao estiramento $\mathrm{C}=\mathrm{O}$ do grupo carboxílico, ausente no espectro da quitosana. Esta banda confirma a enxertia do poli(ácido acrílico) sobre a quitosana. Também é observado neste espectro uma banda de intensidade forte de $1390 \mathrm{~cm}^{-1}$, correspondente ao estiramento $\mathrm{C}-\mathrm{N}$ de amina secundária,

Tabela 1. Grau de enxertia em função das massas de microesferas quitosana

\begin{tabular}{cc}
\hline Quitosana (mg) & Grau de enxertia (\%) \\
\hline 99,3 & $54,9 \pm 1,2$ \\
308,7 & $54,3 \pm 1,1$ \\
313 & $54,5 \pm 1,1$ \\
\hline
\end{tabular}
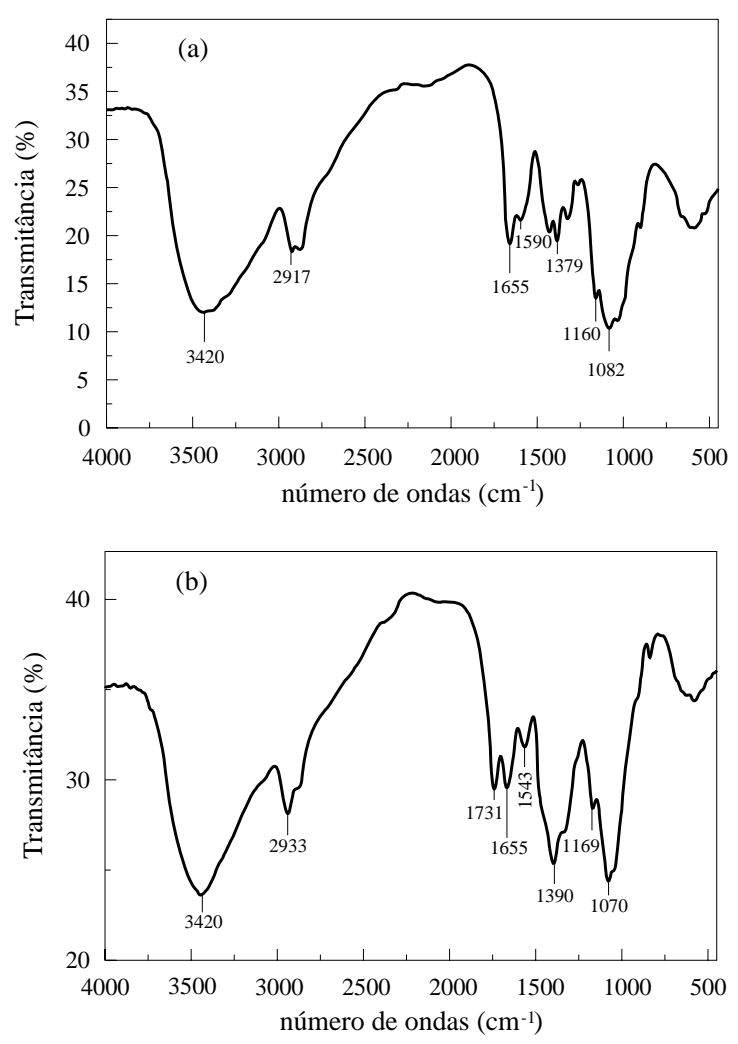

Figura 3. Espectro no infravermelho da quitosana (3a) e da quitosana modificada (3b)

ausente no espectro da quitosana, confirmando a redução do grupos imino da base de Schiff. Uma outra banda em $1543 \mathrm{~cm}^{-1}$, ausente na quitosana, pode ser atribuída ao estiramento da ligação $\mathrm{C}=\mathrm{N}$, o qual corresponderia a alguns grupos imino não reduzidos.

\section{Microscopia eletrônica de varredura}

A impregnação da eosina em microesferas de quitosana enxertada com poli(ácido acrílico) foi confirmada visualmente pela coloração avermelhada característica do corante eosina, na superfície e no interior (seção transversal) das mesmas.

As micrografias de microscopia eletrônica de varredura da seção transversal da microesfera de quitosana modificada contendo ou não eosina são ilustradas na Figura 4.

Nesta figura são observadas morfologias diferentes para seções tranversais das microesferas impregnadas com eosina (Figura 4b) e microesferas sem eosina (Figura 4a). A morfologia das microesferas sem eosina na seção transversal, apresenta-se na forma de escamas e compactada, enquanto que nas microesferas impregnadas com eosina a morfologia é alterada para uma forma de grânulos poligonais. Esta 

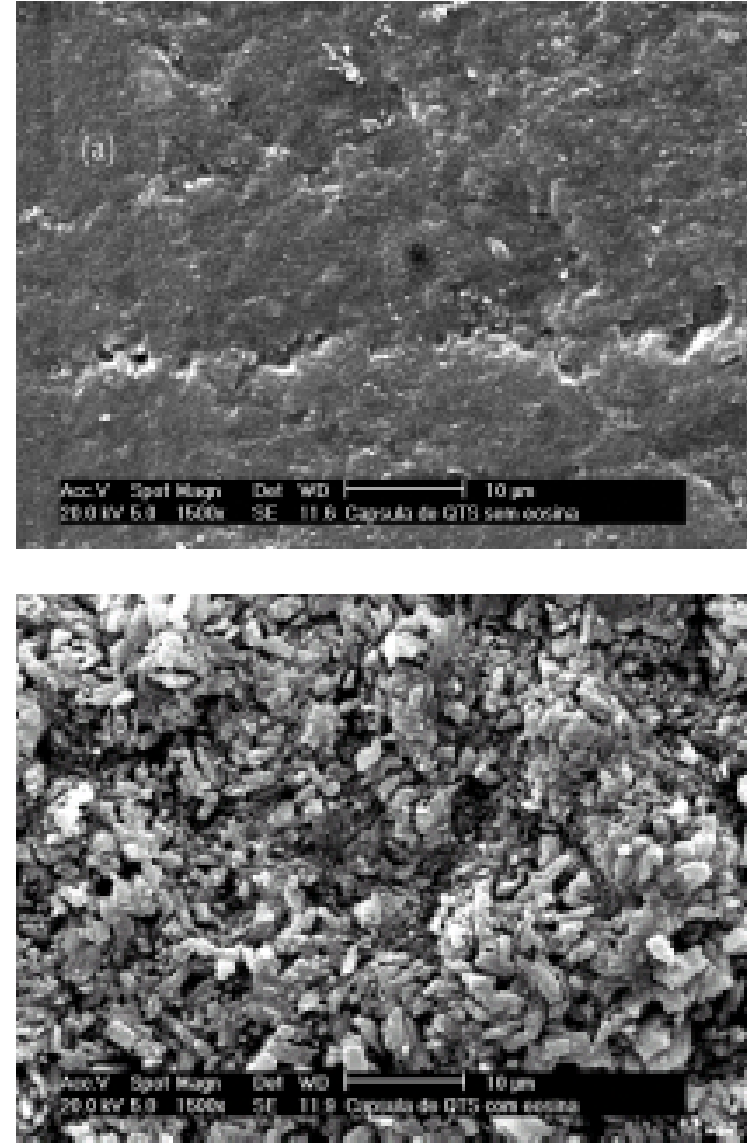

Figura 4. Microscopia eletrônica de varredura (MEV): (b) da seção transversal da microesfera de quitosana modificada contendo eosina; (a) da seção transversal, modificada sem eosina.

diferença na morfologia pode ser atribuída à grande solubilidade da eosina na matriz polimérica.

\section{Liberação "in vitro" da eosina}

$O$ perfil da curva de liberação de eosina em função do tempo de contato das microesferas de quitosana a diferentes $\mathrm{pH}$ 1,2; 6,8 e 9,8 (Figura 5) mostrou ser exponencial, embora não tenha sido realizada uma análise cinética para cada $\mathrm{pH}$.

A Figura mostra que a $\mathrm{pH} 1,2$, o qual simula o trânsito estomacal, não ocorreu a liberação da eosina durante o intervalo de tempo de 0 até 2 horas. Enquanto que a pH 6,8 (simulando o trânsito intestinal) o estudo se estendeu de 2 até 6 horas e nesse intervalo foi observado que $44,1 \%$ da eosina foi liberada. Finalmente a pH 9,8 (simulando o trânsito cecal) e no intervalo de tempo de 6 até 12 horas, a liberação foi de $99,1 \%$.

Para valores de $\mathrm{pH}$ elevados a quitosana possui uma baixa densidade de carga ao contrário do poli(ácido acrílico). O pKa da quitosana que corresponde a cadeia principal do copolímero quitosana/poli(ácido acrílico) é aumentado pela presença do poliânion poliacrilato (cadeias ramificadas enxertadas), sugerindo que o grupo carboxílato induz a ionização do grupo amino da quitosana ${ }^{[13]}$. O copolímero estudado pode ser comparado a um protenóide polipeptídico tendo um grande número de grupos carboxílicos na sua cadeia ${ }^{[23]}$. Assim, um protenóide pode ser carregado tanto positivamente como negativamente, dependendo do $\mathrm{pH}$ do meio, visto que os grupos amino são protonados $\left(-\mathrm{NH}_{3}{ }^{+}\right)$em meio ácido enquanto os grupos carboxílicos são ionizados (- $\left.\mathrm{COO}^{-}\right)$em meio alcalino.

Os dados de liberação da eosina impregnadas nas microesferas durante as 2 horas no fluído gástrico, confirmam que apesar da pequena permeabilidade das microesferas de quitosana neste meio, não ocorreu nenhuma liberação do corante, devido à pouca solubilidade da eosina a qual está protonada neste meio, mas também ao fato do poli(ácido acrílico) ser não ionizados em $\mathrm{pH} 1,2^{[24]}$.

$\mathrm{O}$ copolímero é esperado intumescer em $\mathrm{pH}$ acima de 6,3, que é o pKa da quitosana. No pH 6,8 praticamente a metade dos grupos amino da quitosana estariam protonados, enquanto o poli(ácido acrílico) estaria praticamente ionizado, afetando as propriedades de intumescimento e da liberação da eosina pelas microesferas.

No entanto, a pH 9,8 todos os grupos carboxílicos apresentam-se ionizados e os grupos amino completamente desprotonados. A grande liberação da eosina neste meio, depende além da sensibilidade do copolímero ao $\mathrm{pH}$, das características de intumescimento do copolímero reticulado e da grande solubilidade da eosina no meio alcalino. Por outro lado, o intumescimento do copolímero na sua forma ionizada pode ser atribuído pela diferença nas pressões osmóticas devido à eosina ionizada na microesfera e na solução tampão ${ }^{[25]}$.

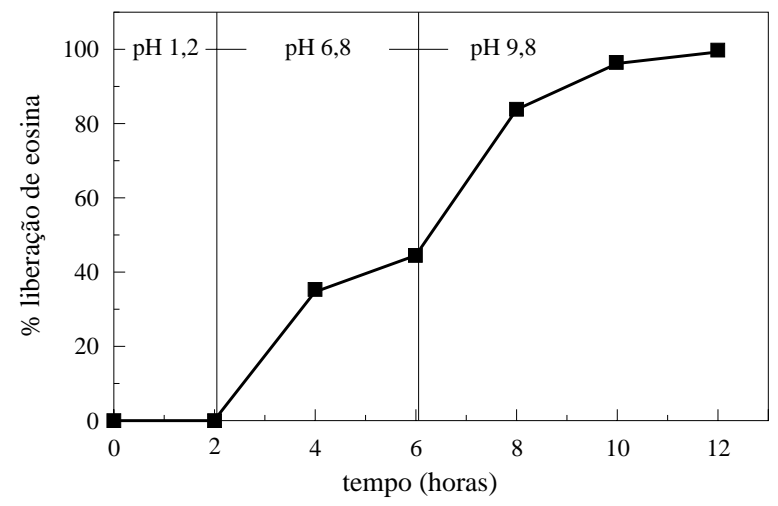

Figura 5. Curva de liberação de eosina em função do tempo 


\section{Conclusões}

Neste estudo foram preparadas microesferas de quitosana reticuladas com glutaraldeído e enxertadas com poli(ácido acrílico) para incorporar o corante eosina como modelo de fármaco de baixa massa molar.

As análises de microscopia eletrônica de varredura indicam que a eosina foi impregnada na superfície e no interior das microesferas funcionalizadas com poli(ácido acrílico).

As microesferas de quitosana-poli(ácido acrílico) apresentaram-se sensíveis ao $\mathrm{pH}$ e foram efetivas como sistema de liberação in vitro de eosina em função do tempo. Estes resultados sugerem que o sistema de liberação estudado poderá ser útil para a administração oral de fármacos.

\section{Referências Bibliográficas}

1. Kazuhiro, I.; Yoshiharu, M. ; Takanori, S. \& Tsuneji, N. - Drug Design and Delivery, 4, p.55 (1989).

2. Florence, A. T. \& Jani, P. U. - Drug safety, 19, p.233 (1994)

3. Silva, J. P. S. \& Ferreira, J. P. M. - Journal of Microencapsulation, 16, p.95 (1999)

4. Lower. E. S. - Manufacturing Chemistry, 9, p.73(1984)

5. Marthur, N.K.; Narang, K.C. - J. Chem. Educ., 67, p.938(1990).

6. Muzzarelli R.A.A. "Natural chelating polymers", Pergamon Press, Oxford (1973).

7. Amano, K. \& Ito E. - Eur. J. Biochem., 85, p.97 (1978).

8. Inoue, K.; Machida, Y,; Sanan, T. \& Nagai, T. - Drug Design and Delivery, 4, p.55 (1989).

9. Polk, A.; Amsdem, B.; Yao, K. D.; Peng, T \& Goosen, M. F. A. - Pharm. sci., 83, p.178 (1994)

10. Açikgöz, M.; Kas, H.S.; Orman, M. and Hincal, A. A. - Journal of microencapsulation, 13, p.141 (1996)
11. Sawayanagi, Y.; Nambu, N. \& Nagai, T. - Chemical and Pharmaceutical Bulletin, 31, p.2064 (1983)

12. Nakamura, F.; Onischi, H. \& Machida, Y. Chemical and Pharmaceutical Bulletin, 52, p.59 1992

13. Akbuga, J. - Internacional Journal of Pharmaceutical Advances, 1, p.3 (1995)

14. Sawayanagi, Y.; Nambu, N. \& Nagai, T. - Chemical and Pharmaceutical Bulletin, 30, p.4213 (1982).

15. Hou, W. -M.; Miyazaki, S.; Takada, M. \& Komai, T. - Chemical and Pharmaceutical Bulletin, 33, p.3986 (1985).

16. Bugamellli, F.; Raggi, M. A.; Orienti, I \& Zechi, V. Arch Pharm. Pharm. Pharm. Med. Chem., 331, p133 (1998)

17. Norobu, N.; Hideki, Y. \& Kosai, K. - J. Appl. Pol. Sci, 40, p. 2007 (1990).

18. Egboh, S.H.O. \& Akonwu, L.N. - Acta Polymerica, 42, p.279 (1991)

19. Broussignac, J. - Chimie industrielle e Génie chimique, 99, p.124 (1970).

20. Kimura, Y. I.; Gonçalves Júnior, C. A.; Stolberg, J.; Laranjeira, M.C.M. \& Fávere, T. V. - Polímero: Ciência e Tecnologia, 3, p.51 (1999).

21. Khertarpal, R. C.; Gill, K. D.; Mehta, I.K. \& Misra, B. N. - J. Macromol. Sci Chem., 18, p.445 (1982).

22. Tozaki, H.; Emi, Y. Horisaka, E.; Fujita, T.; Yamamoto, A. \& Muranishi, S. - J. Pharm. Sci., 49, p.164 (1997).

23. Hideyuki, T.; Junta, K.; Chika, T. \& Takako, M. - J. Pharm. Sci, 86, p.1016 (1997).

24. Narayani, N. K. \& Rao, P. - Journal of Applied Polymer Science, 58, p.1761 (1995).

25. Kubota, N. \& Kikuchi, Y., in "Polyssaccharides" ed by Dimitriu(New York: Marcel Dekker), p.595 (1998).

Recebido: 22/12/99 Aprovado: 24/08/00 